\title{
Taurine effects on Bisphenol A-induced oxidative stress in the mouse testicular mitochondria and sperm motility
}

\author{
Fatemeh Rezaee-Tazangi ${ }^{1}$, Leila Zeidooni ${ }^{3}$, Zeinab Rafiee ${ }^{2}$, Fereshtesadat Fakhredini², Heybatollah Kalantari ${ }^{3}$, \\ Hadis Alidadi ${ }^{3}$, Layasadat Khorsandi ${ }^{2,4}$ \\ ${ }^{1}$ Student Research committee, Ahvaz Jundishapur University of Medical Sciences, Ahvaz, Iran \\ 2Department of Anatomical Sciences, Ahvaz Jundishapur University of Medical Sciences, Ahvaz, Iran \\ ${ }^{3}$ Toxicology Research Center, Ahvaz Jundishapur University of Medical Sciences, Ahvaz, Iran \\ ${ }^{4}$ Cellular and Molecular Research Center, Ahvaz Jundishapur University of Medical Sciences, Ahvaz, Iran
}

\begin{abstract}
Objectives: This study was performed to investigate the protective effects of taurine (2-aminoethanesulfonic acid, TAU) on oxidative stress in the isolated mouse testicular mitochondria, mitochondrial membrane potential (MMP), viability and motility of the exposed sperms to the BPA.
\end{abstract}

Methods: We treated epididymal spermatozoa obtained from mice and isolated mouse testicular mitochondria with BPA $(0.8 \mathrm{mmol} / \mathrm{mL})$ and various doses of TAU $(5,10,30$ and $50 \mu \mathrm{mol} / \mathrm{L})$. We used the MTT assay and Rhodamine 123 uptake to assess sperm viability and MMP. We assessed the oxidative stress through measuring ROS (reactive oxygen species), MDA (malondialdehyde), GSH (glutathione), and SOD (super-oxide dismutase) levels in the testicular mitochondrial tissue.

Results: BPA significantly elevated ROS, MDA and MMP levels, and markedly reduced SOD and GSH levels in the isolated mitochondria. BPA also considerably impaired spermatozoa viability and motility. Pretreatment with 30 and $50 \mu \mathrm{mol} / \mathrm{L}$ of TAU could considerably suppressed mitochondrial oxidative stress, enhanced MMP, and improved sperm motility and viability.

Conclusion: TAU may attenuate the BPA-induced mitochondrial toxicity and impaired sperm motility via decreasing oxidative stress.

Keywords: mitochondria, sperm motility, taurine, oxidative stress, bisphenol A

\section{INTRODUCTION}

Bisphenol A (BPA), a polycarbonate plastic and a constituent of epoxy and polystyrene resins, is used in coatings of beverages, food cans, and baby bottles, and it is used in thermal containers, dental sealants, and medical devices (Vandenberg et al., 2007; Mikołajewska et al., 2015; Anjum et al., 2011). The migration of BPA into the environment depends on $\mathrm{pH}$ and temperature (Scippo, 2011; Braun et al., 2011). BPA enters the body via dermal contact, inhalation and ingestion (Siracusa et al., 2018). The human exposure to BPA depends on the BPA levels in the environment, biological systems, and food intake. There can be BPA in semen, urine, plasma, breast milk and amniotic fluid (Engel et al., 2014; Ye et al., 2006; Ikezuki et al., 2002).

BPA has toxic impacts on various tissues, including the male reproductive system (Ullah et al., 2018; Anjum et al., 2011). BPA can reduce testicular and epididymal weights in rodents (Chitra et al., 2003) and impair sperm quality (Li et al., 2016). In addition, BPA induces mitochondrial dysfunction by reducing ATP, diminishing the mass of mitochondria, and disrupting membrane potential (Kaur et al., 2014; Lin et al., 2013). Mitochondrial dysfunction can affect sperm motility and sperm production (Chattopadhyay et al., 2010). Moreover, BPA suppresses antioxidant activity and enhances ROS production in rat testicles (Chitra et al., 2003).

Taurine (TAU), is a free amino acid, present in several mammalian tissues such as the reproductive system (De Luca et al., 2015; Park et al., 2002). It has several physiological functions, including energy storage, membrane stabilization, xenobiotic conjugation, and antioxidation (Huxtable, 1992). There is TAU in seminal fluid, vascular endothelial cells, germinal cells, Leydig cells and in the covering epithelium of efferent ducts (Holmes et al., 1992; Hinton, 1990). TAU may act as an antioxidant, membrane-stabilizing and motility factors of the sperm (Yang et al., 2015). The current research investigated TAU impacts on BPA-induced mitochondrial oxidative stress and impaired sperm motility in mice.

\section{MATERIALS AND METHODS}

\section{Experimental design}

We collected sperm samples and isolated testicular mitochondria from forty-two adult NMRI mice (8-10 weeks). The Ethics Committee on Animal Research confirmed this study (No: ABHC.REC.1397.079).

We obtained the spermatozoa from the epididymis, as per previously described (Su et al., 2019), and categorized into the following groups (Figure 1 ). In each group, we used $5 \times 10^{6} \mathrm{sperm} / \mathrm{ml}$ (Harris et al., 2007).

1. Control: received only media

2. BPA: exposed to $0.8 \mathrm{mmol} / \mathrm{L}$ BPA for 2 hours

3. TAU: exposed to $50 \mu \mathrm{mol} / \mathrm{L}$ TAU for 4 hours

4. BPA+TAU5: pretreated with $5 \mu \mathrm{mol} / \mathrm{L}$ of TAU for 2 hours before BPA treatment (2 hours).

5. BPA+TAU10: pretreated with $10 \mu \mathrm{mol} / \mathrm{L}$ of TAU for 2 hours before BPA treatment (2 hours).

6. BPA+TAU30: pretreated with $30 \mu \mathrm{mol} / \mathrm{L}$ of TAU for 2 hours before BPA treatment ( 2 hours).

7. BPA+TAU50: pretreated with $50 \mu \mathrm{mol} / \mathrm{L}$ of TAU for 2 hours before BPA treatment ( 2 hours).

We kept all samples at $37^{\circ} \mathrm{C}$ in an incubator during the experiment. The untreated sperms (control groups) began to die after 4 hours. Hence, 4 hours were used to treat the sperms with TAU and BPA. BPA (Sigma) was dissolved in $0.1 \%$ dimethyl sulfoxide (DMSO, Sigma) and then diluted in media (ham's F10, Invitrogen). The BPA dose was chosen according to the $\mathrm{IC}_{50}$ value (Table 1 ). To determine the $\mathrm{IC}_{50}$ of BPA, the sperm 


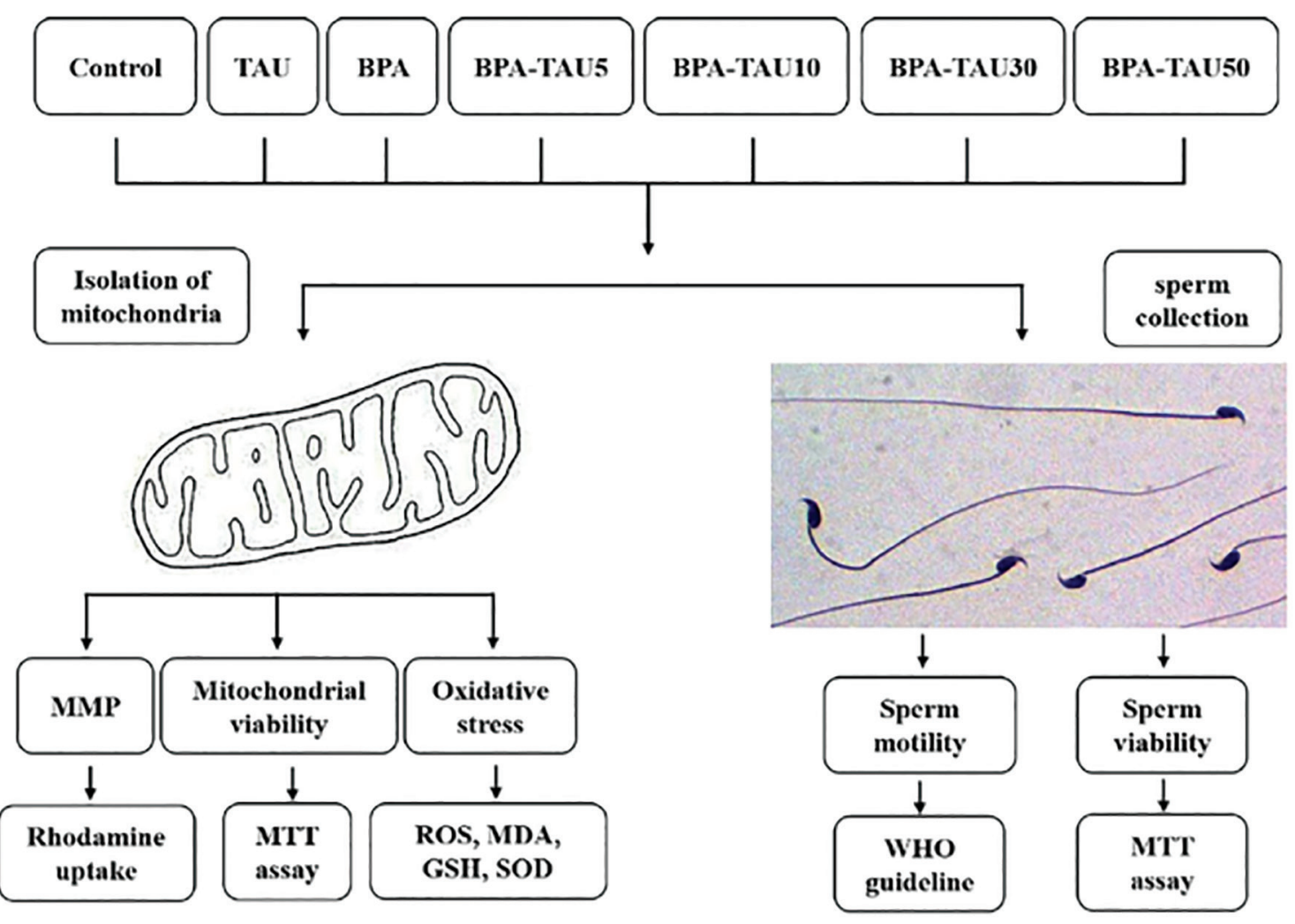

Figure 1. Schematic illustration of experimental design

\begin{tabular}{|c|c|c|}
\hline \multicolumn{3}{|c|}{ Table 1. The $\mathrm{IC}_{50}(\mu \mathrm{M})$ of BPA on the spermatozoa } \\
\hline Concentrations & $\mathbf{1}$ hour & 2 hours \\
\hline $100\left(\mu \mathrm{mol} \mathrm{L}^{-1}\right)$ & $98.7 \pm 4.35$ & $95.4 \pm 6.23$ \\
\hline $200\left(\mu \mathrm{mol} \mathrm{L}^{-1}\right)$ & $91.9 \pm 5.11$ & $85.6 \pm 4.31$ \\
\hline $400\left(\mu \mathrm{mol} \mathrm{L}^{-1}\right)$ & $76.2 \pm 5.65$ & $66.1 \pm 4.37$ \\
\hline $800\left(\mu \mathrm{mol} \mathrm{L}^{-1}\right)$ & $64.1 \pm 4.75$ & $49.5 \pm 3.98$ \\
\hline $1000\left(\mu \mathrm{mol} \mathrm{L}^{-1}\right)$ & $55.2 \pm 3.63$ & $38.3 \pm 3.55$ \\
\hline
\end{tabular}

Values are expressed as mean $\pm S D(n=6)$.

viability was determined using an MTT assay. We dissolved the TAU in distilled water and stored at $4^{\circ} \mathrm{C}$ until use.

\section{Mitochondria isolation}

The mice testicles were removed under deep anesthesia and minced in a cold isolating medium which contained EDTA (0.1 mmol, Sigma), EGTA (0.2 mmol, Sigma), sucrose (250 mmol, Sigma), HEPES-KOH (5 mmol, Sigma) and $0.1 \%$ fat free BSA (bovine serum albumin, Invitrogen). The minced blood-free testicles were homogenized and centrifuged at $3000 \cdot \mathrm{g}$ for 7 minutes (at $4^{\circ} \mathrm{C}$ ). The supernatant was centrifuged at $10,000 \cdot \mathrm{g}$ for 7 minutes. The obtained pellet (mitochondrial fraction) was suspended and pelleted twice at $10,000 \cdot \mathrm{g}$ for 10 minutes. After washing, the protein content was determined using the Bradford assay reagent (Bio-RAD). We divided the isolated mitochondria into 7 groups, similar to the sperm groups, and the mitochondrial fractions ( $0.5 \mathrm{mg}$ protein $/ \mathrm{mL}$ ) were exposed to the similar concentration and duration time of BPA and TAU.

\section{MTT assay}

The isolated mitochondria or sperms were placed in a 96 well plate and treated with BPA or TAU. Ten $\mu \mathrm{L}$ of MTT (Sigma, USA) at concentration of $5 \mathrm{mg} / \mathrm{mL}$ media was poured into each well and incubated at $37^{\circ} \mathrm{C}$ for one hour. When the media was removed, $100 \mu \mathrm{L}$ of DMSO was poured into the wells. Finally, the absorbance at $570 \mathrm{~nm}$ was determined using a micro-plate reader.

Determining MDA content, ROS level and anti-oxidant enzyme activity

After treatment, we poured the isolated mitochondria samples $(1 \mathrm{~mL})$ into the micro-tubes. We removed the media and added $10 \mu \mathrm{mol}$ of DCFH-DA (Sigma) and $100 \mu \mathrm{l}$ of Hank's buffered salt solution (Invitrogen) at $37^{\circ} \mathrm{C}$ for 30 minutes. We measured ROS levels using a spectro-fluorometer (LS50B, USA, Ex: 490 nm, Em: 570 $\mathrm{nm})$. After treatment, we identified the protein contents of the isolated mitochondria using a BCA protein assay kit (Pierce Biotechnology Inc. IL). After centrifuging, we evaluated the malondialdehyde (MDA) content, and the level of GSH (glutathione) and superoxide dismutase (SOD) according to the kit's instruction (ZellBio Company). 
Mitochondrial membrane potential (MMP) evaluation

After treatment, we exposed the fractions of mitochondria ( $0.5 \mathrm{mg}$ protein $/ \mathrm{mL}$ ) to ten $\mu \mathrm{mol}$ of Rhodamine 123 for 15 minutes. We measured the fluorescence using a spectrophotometer (LS50B, USA; excitation: 490 $\mathrm{nm}$; emission: $535 \mathrm{~nm}$ ).

\section{Sperm motility}

We assessed sperm motility according to the WHO guidelines (Su et al., 2019), using ten $\mu \mathrm{L}$ of sperm suspension poured into a semen analysis chamber. We evaluated five microscopic fields to estimate sperm motility on at least 200 spermatozoa for each sample, assessing the percentage of sperm motility using the following motion patterns: fast progressive (A), slow progressive (B) no progressive $C$ ) and immotile sperms (D).

\section{Statistical Analysis}

We analyzed the data using the SPSS (version 21.0, employing one-way analysis of variance, post-hoc test, and Bonferroni correction. In addition, the $p$-value $<0.05$ was considered significant.

\section{RESULTS}

Viability

As reported in Figure 2, following BPA exposure, viability percentage significantly reduced in the isolated testicular mitochondria and spermatozoa $(p<0.01)$.
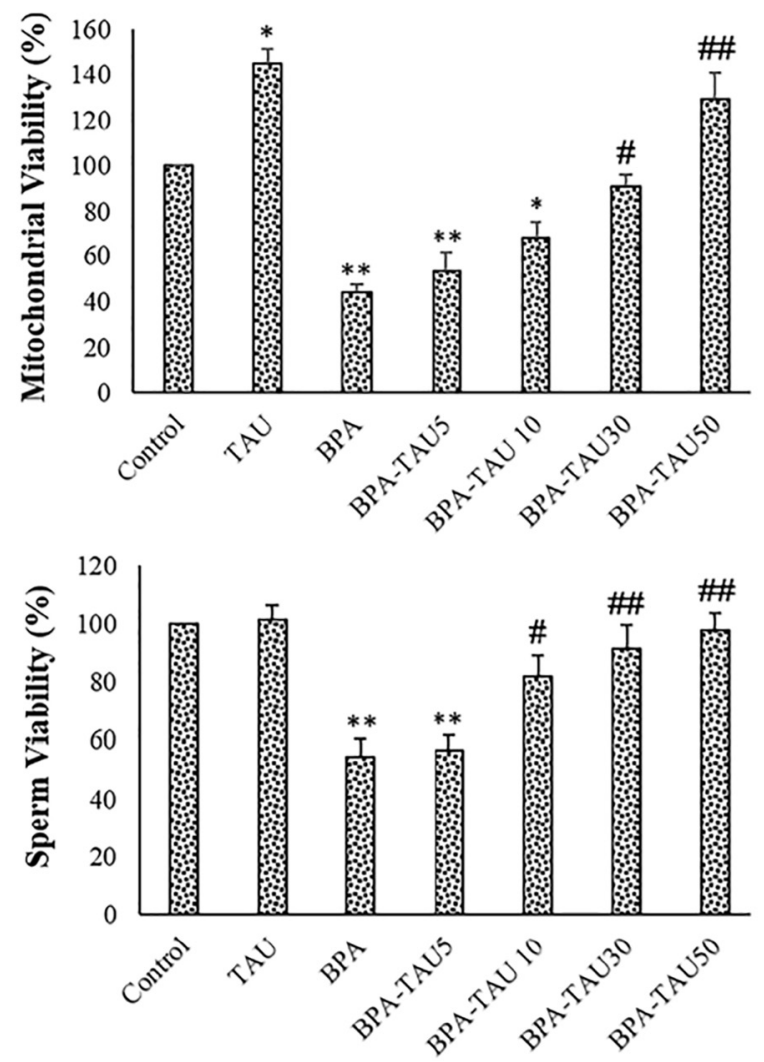

Figure 2. Viability percentage of the isolated mitochondria and sperms. The mean \pm standard deviations are shown $(n=6)$.* $p<0.05, * * p<0.01, \# p<0.05, \# \# p<0.01 ; *$ and \# symbols show comparison to the control and BPA groups, respectively.
The viability percentage significantly increased in the TAU-exposed mitochondria $(p<0.05)$. TAU at the doses of 30 and $50 \mu \mathrm{mol} / \mathrm{L}$ reversed the viability of the BPA-exposed sperms and the testicular mitochondria. DMSO did not significantly affect sperm viability and motility (Table 2).

\section{ROS measurement}

In the BPA group, the ROS generation was considerably elevated in the testicular mitochondria $(p<0.01)$. ROS generation was significantly reduced in the TAU treated samples in comparison with the control. TAU dose-dependently attenuated ROS production by BPA in the testicular mitochondria (Figure 3). DMSO had no significant impact on ROS formation in comparison with the control (Table 2).

\section{MDA, SOD and GSH levels}

Following BPA exposure, MDA levels were significantly increased in the isolated testicular mitochondria compared to the control $(p<0.01)$. MDA levels were slightly reduced in the TAU-treated mitochondria in comparison with the control. At the doses of 10,30 and $50 \mu \mathrm{mol} / \mathrm{L}$, TAU attenuated BPA increased MDA levels in the testicular mitochondria. SOD and GSH levels were considerably elevated in the BPA-exposed mitochondria $(p<0.01)$. Following TAU treatment, SOD levels were slightly increased while GSH levels were significantly elevated, compared to the control. In a dose-dependent fashion, TAU attenuated BPA- reduced antioxidant activity in the testicular mitochondria (Figure 4). DMSO had no significant impact on MDA, SOD and GSH levels in the mitochondria (Table 2).

\section{MMP Assay}

As reported in Figure 5, TAU significantly increased MMP in the testicular mitochondria $(p<0.05)$. Following BPA exposure, MMP was significantly reduced compared to the control $(p<0.01)$. TAU at the doses of 10,30 and $50 \mu \mathrm{mol} / \mathrm{L}$ effectively enhanced the MMP of the BPA-treated mitochondria. DMSO had no significant impacts on the MMP in comparison to the control (Table 2).

\section{Sperm motility}

TAU slightly increased total sperm motility in comparison to the control. Following BPA exposure, total sperm motility $(p<0.01)$ and fast progressive sperm percentages $(p<0.05)$ were significantly reduced, while immotile sperm percentage was markedly increased $(p<0.01)$. TAU dose-dependently reversed the total sperm motility, fast progressive sperm percentages, and the percentage of immotile sperms (Table 3 and Figure 6). DMSO had no significant impacts on sperm motility when compared to the control (Table 3).

\section{DISCUSSION}

Our study showed that TAU reversed the viability and motility of the BPA-exposed sperms in a dose-dependent fashion. Previous reports showed that BPA caused a decrease in sperm quality in rodents and humans (Rahman et al., 2016; Wisniewski et al., 2015; Kotwicka et al., 2016). BPA impaired reproduction and sperm function in zebrafish (Chen et al., 2017). BPA decreased the viability of the mouse spermatocyte (Qian et al., 2015).

In this study, TAU dose-dependently improved viability, motility and progressive movement velocity of BPA-treated 


\begin{tabular}{|l|c|c|}
\hline Table 2. DMSO effects on isolated mitochondria and sperms \\
\hline Parameters & Control & DMSO \\
\hline Sperm viability of (\%) & $100 \pm 0.00$ & $99.6 \pm 1.16$ \\
\hline Mitochondria viability (\%) & $100 \pm 0.00$ & $100.05 \pm 0.94$ \\
\hline MMP (\% of control) & $100 \pm 0.00$ & $98.7 \pm 2.35$ \\
\hline ROS formation (\% of control) & $100 \pm 0.00$ & $17.9 \pm 3.36$ \\
\hline Mitochondria MDA (nmol/ mg protein) & $18.2 \pm 5.65$ & $49.5 \pm 3.98$ \\
\hline Mitochondria GSH (pmol/ mg protein) & $11.51 \pm 2.75$ & $9.92 \pm 2.16$ \\
\hline Mitochondria SOD (U/ mg protein) & $10.28 \pm 2.65$ & $71.32 \pm 6.45$ \\
\hline Total sperm motility (\%) & $69.85 \pm 5.78$ & \\
\hline
\end{tabular}

Values are expressed as mean $\pm S D(n=6)$.

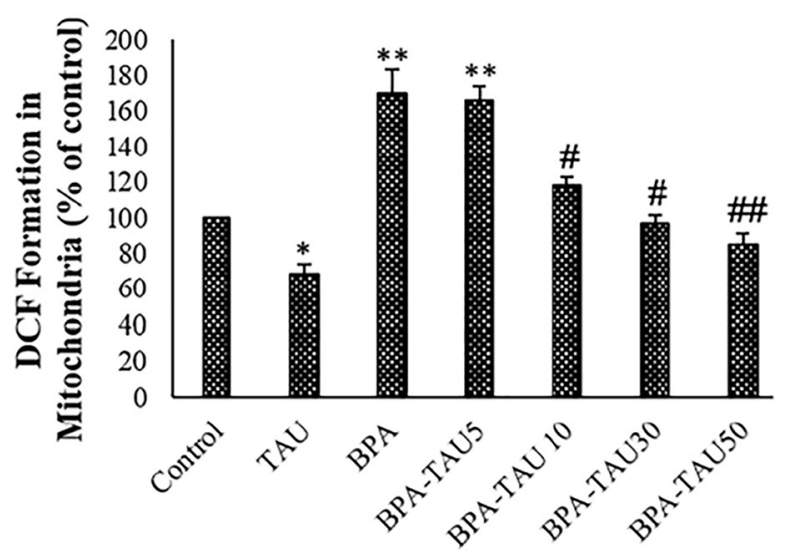

Figure 3. DCF formation (ROS levels) in the spermatozoa and isolated mitochondria. The mean \pm standard deviations are shown $(n=6) . *$ and \# symbols show a comparison of the control and BPA groups, respectively.

mouse sperms. In agreement with our results, Yang et al. (2017) reported that TAU effectively protects GC-2 (spermatocytes) cells from ionizing radiation. TAU dose-dependently enhanced sperm quality in donkeys (Bottrel et al., 2018). Positive effects of TAU on boar semen quality have also been reported ( $\mathrm{Li}$ et al., 2016; Kutluyer et al., 2016). Conversely, BPA has no impact on fowl sperm motility (Barna et al., 1998), and it has no positive effects on the viability of short-term (4 hours) stored rabbit spermatozoa (Paál et al., 2017). The difference in treatment duration or species variety may represent the reasons for these contradictory results.

The mechanism of TAU action on sperm viability and motility was not elucidated in the current study. It is possible that TAU improves sperm viability via suppression of cell death signaling. Aly \& Khafagy (2014) showed the anti-apoptotic effects of TAU against endosulfan in adult rat testicles. TAU inhibited apoptosis in Thiopurine-induced testicular damages in rats (Ramadan et al., 2018). Improved sperm motility may be due to TAU impacts in mitochondrial mass or function.

It has been reported that TAU exists in the mitochondrial matrix and membranes of various cells (Jong et al., 2010; Alvarez \& Storey, 1995; Hansen et al., 2010; Shetewy et al., 2016). Mitochondria has a TAU transporter in its plasma membrane to uptake TAU from culture media (Suzuki et al., 2002). Thus, adding TAU to culture media
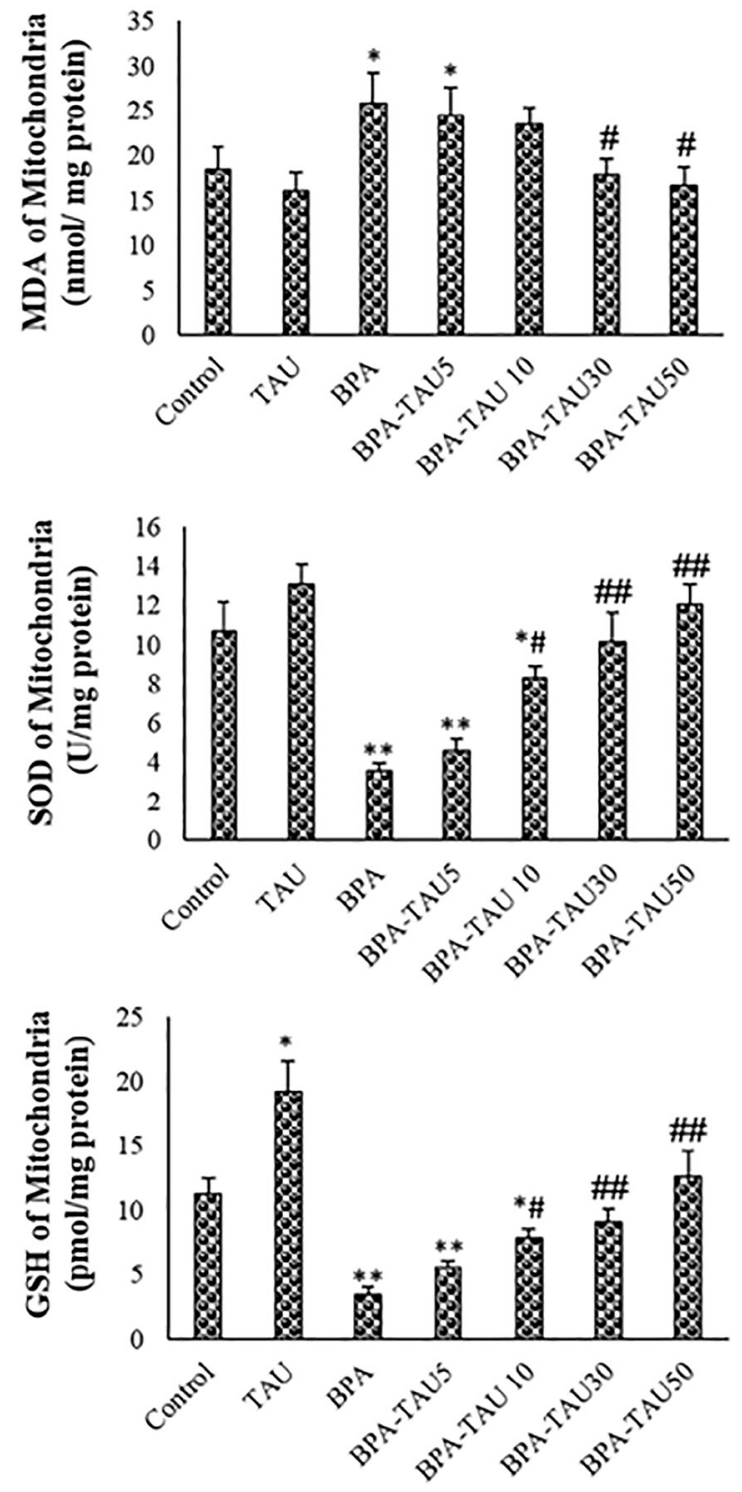

Figure 4. MDA, SOD and GSH levels of mice spermatozoa. The mean \pm standard deviations are shown $(n=6)$. MDA, SOD and GSH levels of the isolated mitochondria. The mean \pm standard deviations are shown $(n=6) . *$ and \# symbols show a comparison of the control and BPA groups, respectively. 


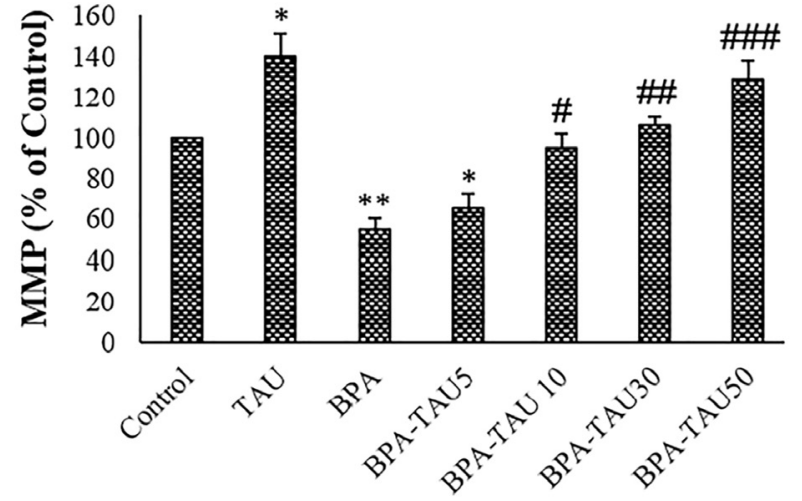

Figure 5. MMP measurement in the control and experimental groups. The mean \pm standard deviations are shown $(\mathrm{n}=6)$.\#\#\# $p<0.001 ; *$ and \# symbols show a comparison of the control and BPA groups, respectively.

may enhance its concentration in the mitochondria and improve mitochondrial function.

The disrupted sperm movement can also be due to high ROS levels (Barbonetti et al., 2016). According to our results, BPA enhanced ROS and MDA levels in the spermatozoa. In agreement with these findings, BPA enhanced ROS generation and MDA contents in the spermatozoa (Kaur et al., 2018; Yang et al., 2013; Yang et al., 2017; Rahman et al., 2019).

The present study has shown that TAU reversed ROS generation, MDA level, antioxidant factors, and MMP in the BPA-exposed mouse testicular mitochondria. Therefore, TAU may protect mitochondria by reducing oxidative stress. Consistent with our results, TAU had protective impacts on mitochondrial oxidative damage in various pathological conditions. TAU improves the function of heart mitochondria and prevents oxidative stress in diabetic rats (Gorbenko et al., 2016). TAU inhibits mitochondrial oxidative damage induced by Tamoxifen in the mouse liver (Parvez et al., 2008).
The TAU-reversed oxidative stress induced by BPA was accompanied by increasing sperm motility and viability. In the study of Minamiyama et al. (2010), BPA-decreased sperm motility was reversed by co-administering n-acetylcysteine. Wisniewski et al. (2015) demonstrated that TAU elevated anti-oxidation of the testis and enhance sperm quality.

According to our results, BPA diminished the MMP of the isolated mouse testicular mitochondria, and TAU dose-dependently reversed this event. BPA decreased the MMP and increased cell death in human spermatozoa (Barbonetti et al., 2016). MMP was positively correlated with total sperm number and progressive sperm motility (Zhang et al., 2016).

The BPA reduced MMP was accompanied by the induced mitochondrial oxidative stress and impaired sperm motility. BPA is reported to cause oxidative stress in the mitochondria obtained from testicles, leading to an elevation in lipid peroxidation (del Hoyo et al., 2010). Lipid peroxidation, in turn, can disrupt spermatozoa functions (Catalá, 2009).

Lipid peroxidation in mitochondria can be reversed by TAU administration (Parvez et al., 2008). TAU could prevent manganese-induced mitochondrial damages in isolated mice brain mitochondria (Ahmadi et al., 2018).

\section{CONCLUSIONS}

In summary, TAU dose-dependently decreased mitochondrial oxidative stress and improved MMP. In addition, TAU improved the viability and motility of mice sperm. TAU can ameliorate BPA-induced mitochondrial toxicity and impaired sperm quality by suppressing oxidative stress.

\section{ACKNOWLEDGMENT}

Student Research committee of Ahvaz Jundishapur University funded this work (funding number: 97s26).

\section{CONFLICT OF INTEREST}

The authors declare no conflict of interest.

\section{Corresponding author:}

Layasadat Khorsandi

Department of Anatomical Sciences

Ahvaz Jundishapur University of Medical Sciences

Ahvaz, Iran.

E-mail: khorsandi_cmrc@yahoo.com

Table 3. Velocity distribution of spermatozoa in different groups

\begin{tabular}{|l|c|c|c|c|}
\hline Groups & Fast progressive & Slow progressive & No progressive & Immotile \\
\hline Control & $39.77 \pm 4.11$ & $30.27 \pm 3.83$ & $17.11 \pm 2.46$ & $12.85 \pm 2.86$ \\
\hline TAU & $42.54 \pm 3.36$ & $33.62 \pm 4.18$ & $16.17 \pm 2.53$ & $7.67 \pm 1.12^{*}$ \\
\hline BPA & $25.77 \pm 2.27^{*}$ & $21.85 \pm 2.14^{*}$ & $22.58 \pm 3.25$ & $29.17 \pm 2.67 *$ \\
\hline BPA-TAU2.5 & $31.97 \pm 3.15$ & $19.25 \pm 2.19$ & $24.95 \pm 2.71$ & $25.67 \pm 3.17^{*}$ \\
\hline BPA-TAU5 & $32.53 \pm 4.2$ & $21.62 \pm 3.11$ & $22.92 \pm 3.33$ & $22.93 \pm 2.88 *$ \\
\hline BPA-TAU10 & $36.15 \pm 4.5^{\#}$ & $31.87 \pm 4.21$ & $21.67 \pm 3.52$ & $10.31 \pm 1.89$ \\
\hline BPA-TAU20 & $41.26 \pm 5.1^{\# \#}$ & $30.25 \pm 3.92$ & $20.15 \pm 2.91$ & $8.34 \pm 1.12^{\# \#}$ \\
\hline
\end{tabular}

The mean \pm standard deviations are shown $(n=6) . * p<0.05,{ }^{*} p<0.05,{ }^{*} p<0.01 ; *$ and ${ }^{*}$ symbols show comparison to the control and BPA groups, respectively. 


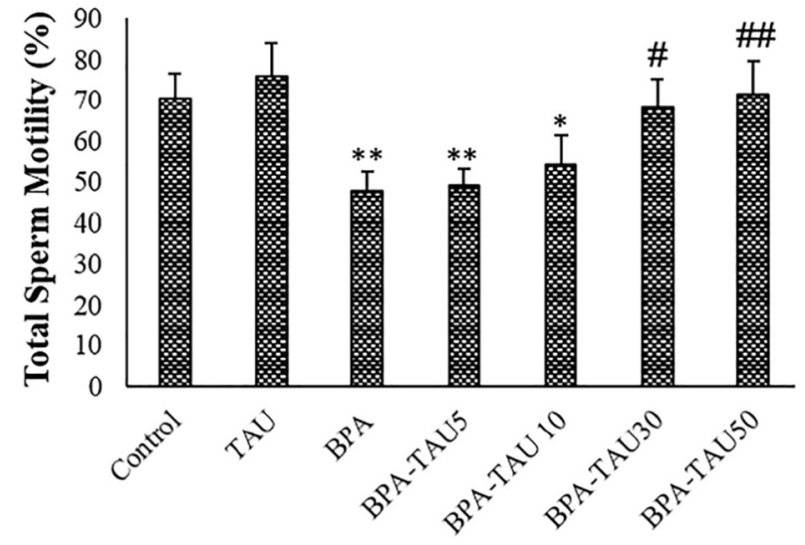

Figure 6. Total sperm motility in the different groups. The mean \pm standard deviations are shown $(n=6) .^{*}$ and \# symbols show a comparison to the control and BPA groups, respectively.

\section{REFERENCES}

Ahmadi N, Ghanbarinejad V, Ommati MM, Jamshidzadeh A, Heidari R. Taurine prevents mitochondrial membrane permeabilization and swelling upon interaction with manganese: Implication in the treatment of cirrhosis-associated central nervous system complications. J Biochem Mol Toxicol. 2018;32:e22216. PMID: 30152904 DOI: 10.1002/ jbt.22216

Alvarez JG, Storey BT. Differential incorporation of fatty acids into and peroxidative loss of fatty acids from phospholipids of human spermatozoa. Mol Reprod Dev. 1995;42:33446. PMID: 8579848 DOI: 10.1002/mrd.1080420311

Aly HA, Khafagy RM. Taurine reverses endosulfan-induced oxidative stress and apoptosis in adult rat testis. Food Chem Toxicol. 2014;64:1-9. PMID: 24262488 DOI: 10.1016/j.fct.2013.11.007

Anjum S, Rahman S, Kaur M, Ahmad F, Rashid H, Ansari RA, Raisuddin S. Melatonin ameliorates bisphenol A-induced biochemical toxicity in testicular mitochondria of mouse. Food Chem Toxicol. 2011;49:2849-54. PMID: 21840368 DOI: $10.1016 /$ j.fct.2011.07.062

Barbonetti A, Castellini C, Di Giammarco N, Santilli G, Francavilla S, Francavilla F. In vitro exposure of human spermatozoa to bisphenol A induces pro-oxidative/apoptotic mitochondrial dysfunction. Reprod Toxicol. 2016;66:61-7. PMID: 27686954 DOI: 10.1016/j.reprotox.2016.09.014

Barna J, Ashizawa K, Boldizsár H, Inoue M. Effects of taurine on the motility and intracellular free $\mathrm{Ca} 2+$ concentration of fowl spermatozoa in vitro. J Reprod Fertil. 1998;114:2259. PMID: 10070351 DOI: 10.1530/jrf.0.1140225

Bottrel M, Acha D, Ortiz I, Hidalgo M, Gósalvez J, Camisão J, Dorado J. Cryoprotective effect of glutamine, taurine, and proline on post-thaw semen quality and DNA integrity of donkey spermatozoa. Anim Reprod Sci. 2018;189:128-35. PMID: 29325880 DOI: 10.1016/j.anireprosci.2017.12.021
Braun JM, Kalkbrenner AE, Calafat AM, Yolton K, Ye X, Dietrich KN, Lanphear BP. Impact of early-life bisphenol A exposure on behavior and executive function in children. Pediatrics. 2011;128:873-82. PMID: 22025598 DOI: $10.1542 /$ peds.2011-1335

Catalá A. Lipid peroxidation of membrane phospholipids generates hydroxyl-alkenals and oxidized phospholipids active in physiological and/or pathological conditions. Chem Phys Lipids. 2009;157:1-11. PMID: 18977338 DOI: 10.1016/j.chemphyslip.2008.09.004

Chattopadhyay S, Choudhury S, Roy A, Chainy GB, Samanta L. T3 fails to restore mitochondrial thiol redox status altered by experimental hypothyroidism in rat testis. Gen Comp Endocrinol. 2010;169:39-47. PMID: 20678500 DOI: $10.1016 /$ j.ygcen.2010.07.014

Chen J, Saili KS, Liu Y, Li L, Zhao Y, Jia Y, Bai C, Tanguay RL, Dong Q, Huang C. Developmental bisphenol A exposure impairs sperm function and reproduction in zebrafish. Chemosphere. 2017;169:262-70. PMID: 27880925 DOI: 10.1016/j.chemosphere.2016.11.089

Chitra KC, Latchoumycandane C, Mathur PP. Induction of oxidative stress by bisphenol $A$ in the epididymal sperm of rats. Toxicology. 2003;185:119-27. PMID: 12505450 PMID: 12505450 DOI: $10.1016 /$ S0300-483X(02)00597-8

De Luca A, Pierno S, Camerino DC. Taurine: the appeal of a safe amino acid for skeletal muscle disorders. J Transl Med. 2015;13:243. PMID: 26208967 DOI: 10.1186/s12967015-0610-1

del Hoyo P, García-Redondo A, de Bustos F, Molina JA, Sayed $Y$, Alonso-Navarro H, Caballero L, Arenas J, Agúndez JA, Jiménez-Jiménez FJ. Oxidative stress in skin fibroblasts cultures from patients with Parkinson's disease. BMC Neurol. 2010;10:95. PMID: 20958999 DOI: 10.1186/14712377-10-95

Engel LS, Buckley JP, Yang G, Liao LM, Satagopan J, Calafat AM, Matthews CE, Cai $Q$, Ji BT, Cai $H$, Engel SM, Wolff MS, Rothman N, Zheng W, Xiang YB, Shu XO, Gao YT, Chow WH. Predictors and variability of repeat measurements of urinary phenols and parabens in a cohort of Shanghai women and men. Environ Health Perspec. 2014;122:73340. PMID: 24659570 DOI: 10.1289/ehp.1306830

Gorbenko N, Borikov O, Ivanova O, Zvyagina T, Taran K, Kiprich T, Shalamay A. Taurine ameliorates mitochondrial dysfunction and oxidative stress in the heart of rats with type 2 diabetes. Diabetes Metab. 2016;42:294. DOI: 10.1016/j.diabet.2016.07.005

Hansen SH, Andersen ML, Cornett C, Gradinaru R, Grunnet $\mathrm{N}$. A role for taurine in mitochondrial function. J Biomed Sci. 2010;17:S23. PMID: 20804598 DOI: 10.1186/14230127-17-S1-S23

Harris T, Marquez B, Suarez S, Schimenti J. Sperm motility defects and infertility in male mice with a mutation in Nsun7, a member of the Sun domain-containing family of putative RNA methyltransferases. Biol Reprod. 2007;77:376-82. PMID: 17442852 DOI:10.1095/biolreprod.106.058669 
Hinton BT. The testicular and epididymal luminal amino acid microenvironment in the rat. J Androl. 1990;11:498-505. PMID: 2086576 DOI: 10.1002/j.1939-4640.1990.tb00186.x

Holmes RP, Goodman HO, Shihabi ZK, Jarow JP. The taurine and hypotaurine content of human semen. J Androl. 1992;13:289-92. PMID: 1601750 DOI: 10.1002/j.19394640.1992.tb00317.x

Huxtable RJ. Physiological actions of taurine. Physiol Rev. 1992;72:101-63. PMID: 1731369 DOI: 10.1152/physrev.1992.72.1.101

Ikezuki Y, Tsutsumi O, Takai Y, Kamei Y, Taketani Y. Determination of bisphenol A concentrations in human biological fluids reveals significant early prenatal exposure. Hum Reprod. 2002;17:2839-41. PMID: 12407035 DOI: 10.1093/ humrep/17.11.2839

Jong CJ, Ito T, Mozaffari M, Azuma J, Schaffer S. Effect of beta-alanine treatment on mitochondrial taurine level and 5-taurinomethyluridine content. J Biomed Sci. 2010;17:S25. PMID: 20804600 DOI: 10.1186/14230127-17-S1-S25

Kaur K, Chauhan V, Gu F, Chauhan A. Bisphenol A induces oxidative stress and mitochondrial dysfunction in lymphoblasts from children with autism and unaffected siblings. Free Radic Biol Med. 2014;76:25-33. PMID: 25101517 DOI: $10.1016 /$ j.freeradbiomed.2014.07.030

Kaur S, Saluja M, Bansal MP. Bisphenol A induced oxidative stress and apoptosis in mice testes: Modulation by selenium. Andrologia. 2018;50:e12834. PMID: 28719015 DOI: 10.1111 /and. 12834

Kotwicka M, Skibinska I, Piworun N, Jendraszak M, Chmielewska $M$, Jedrzejczak P. Bisphenol A modifies human spermatozoa motility in vitro. J Med Sci. 2016;85:39-45.

Kutluyer F, Öğretmen F, Inanan BE. Cryopreservation of goldfish (Carassius auratus) spermatozoa: effects of extender supplemented with taurine on sperm motility and DNA damage. Cryo Letters. 2016;37:41-6. PMID: 26964024

Li J, Mao R, Zhou Q, Ding L, Tao J, Ran MM, Gao ES, Yuan W, Wang JT, Hou LF. Exposure to bisphenol A (BPA) in Wistar rats reduces sperm quality with disruption of ERK signal pathway. Toxicol Mech Methods. 2016;26:180-8. PMID: 26862991 DOI: $10.3109 / 15376516.2016 .1139024$

Lin Y, Sun X, Qiu L, Wei J, Huang Q, Fang C, Ye T, Kang M, Shen $\mathrm{H}$, Dong $\mathrm{S}$. Exposure to bisphenol $\mathrm{A}$ induces dysfunction of insulin secretion and apoptosis through the damage of mitochondria in rat insulinoma (INS-1) cells. Cell Death Dis. 2013;4:e460. PMID: 23328667 DOI: 10.1038/ cddis.2012.206

Mikołajewska K, Stragierowicz, J, Gromadzińska J. Bisphenol A - Application, sources of exposure and potential risks in infants, children and pregnant women. Int J Occup Med Environ Health. 2015;28:209-41. PMID: 26182919 DOI: 10.13075/ijomeh.1896.00343
Minamiyama Y, Ichikawa H, Takemura S, Kusunoki H, Naito $Y$, Yoshikawa $T$. Generation of reactive oxygen species in sperms of rats as an earlier marker for evaluating the toxicity of endocrine-disrupting chemicals. Free Radic Res. 2010;44:1398-406. PMID: 20815788 DOI: $10.3109 / 10715762.2010 .510523$

Paál D, Strejček F, Tvrdá E, Vašíček J, Baláži A, Chrenek P, Massányi P. Taurine does not improve the quality of shortterm stored rabbit spermatozoa in vitro. Reprod Domest Anim. 2017;52:1046-51. PMID: 28695635 DOI: 10.1111/ rda.13022

Park E, Park SY, Wang C, Xu J, LaFauci G, Schuller-Levis G. Cloning of murine cysteine sulfinic acid decarboxylase and its mRNA expression in murine tissues. Biochim Biophys Acta. 2002;1574:403-6. PMID: 11997111. DOI: 10.1016/ s0167-4781(01)00364-5

Parvez S, Tabassum H, Banerjee BD, Raisuddin S. Taurine prevents tamoxifen-induced mitochondrial oxidative damage in mice. Basic Clin Pharmacol Toxicol. 2008;102:382-7. PMID: 18312495 DOI: $10.1111 / j .1742-$ 7843.2008.00208.x

Qian WY, Wang YX, Zhu JY, Mao CF, Wang Q, Huan F, Cheng J, Liu YQ, Wang J, Xiao $\mathrm{H}$. The toxic effects of bisphenol $A$ on the mouse spermatocyte GC-2 cell line: the role of the $\mathrm{Ca} 2+-$ calmodulin-Ca2+/calmodulin-dependent protein kinase II axis. J Appl Toxicol. 2015;35:1271-7. PMID: 26096086 DOI: $10.1002 /$ jat.3188

Rahman MS, Kang KH, Arifuzzaman S, Pang WK, Ryu DY, Song WH, Park YJ, Pang MG. Effect of antioxidants on BPA-induced stress on sperm function in a mouse model. Sci Rep. 2019;9:10584. PMID: 31332285 DOI: 10.1038/ s41598-019-47158-9

Rahman MS, Kwon WS, Karmakar PC, Yoon SJ, Ryu BY, Pang MG. Gestational Exposure to Bisphenol A Affects the Function and Proteome Profile of F1 Spermatozoa in Adult Mice. Environ Health Perspect. 2016;125:238-45. PMID: 27384531 DOI: $10.1289 /$ EHP378

Ramadan BK, Schaalan MF, Mahmoud ES. Protective effect of taurine on thiopurine-induced testicular atrophy in male albino rats. J Steroids Horm Sci. 2018;9:1000192. DOI: 10.4172/2157-7536.1000192

Scippo ML. Bisphenol A in our food: same toxicological studies but different risk assessment and risk management decisions around the world. Food Sci Law. 2011;5:9-13.

Shetewy A, Shimada-Takaura K, Warner D, Jong CJ, Mehdi $A B$, Alexeyev M, Takahashi K, Schaffer SW. Mitochondrial defects associated with $\beta$-alanine toxicity: relevance to hyper-beta-alaninemia. Mol Cell Biochem. 2016;416:11-22. PMID: 27023909 DOI: 10.1007/s11010-016-2688-z

Siracusa JS, Yin L, Measel E, Liang S, Yu X. Effects of bisphenol $A$ and its analogs on reproductive health: A mini review. Reprod Toxicol. 2018;79 96-123. PMID: 29925041 DOI: $10.1016 /$ j.reprotox.2018.06.005 
Su Q, Chen $Y$, Qin J, Li H, Liu M, Zhang Z, Liu Q. Ratio-dependent effects of quinestrol and levonorgestrel compounds (EP-1) on reproductive parameters of adult male Swiss mice. Pestic Biochem Physiol. 2019;160:1816. PMID: 31519253 DOI: 10.1016/j.pestbp.2019.08.009

Suzuki T, Suzuki T, Wada T, Saigo K, Watanabe K. Taurine as a constituent of mitochondrial tRNAs: new insights into the functions of taurine and human mitochondrial disease. EMBO J. 2002;21:6581-9. PMID: 12456664 DOI: 10.1093/ emboj/cdf656

Ullah A, Pirzada $M$, Jahan $S$, Ullah $H$, Shaheen $G$, Rehman $H$, Siddiqui MF, Butt MA. Bisphenol $A$ and its analogs bisphenol B, bisphenol F, and bisphenol S: Comparative in vitro and in vivo studies on the sperms and testicular tissues of rats. Chemosphere. 2018;209:508-16. PMID: 29940534 DOI: 10.1016/j.chemosphere.2018.06.089

Vandenberg LN, Hauser R, Marcus M, Olea N, Welshons WV. Human exposure to bisphenol A (BPA). Reprod Toxicol. 2007;24:139-77. PMID: 17825522 DOI: $10.1016 / \mathrm{j}$. reprotox.2007.07.010

Wisniewski P, Romano RM, Kizys MM, Oliveira KC, Kasamatsu T, Giannocco G, Chiamolera MI, Dias-da-Silva MR, Romano MA. Adult exposure to bisphenol A (BPA) in Wistar rats reduces sperm quality with disruption of the hypothalamic-pituitary-testicular axis. Toxicology. 2015;2:329:19. PMID: 25575453 DOI: 10.1016/j.tox.2015.01.002
Yang J, Zong X, Wu G, Lin S, Feng Y, Hu J. Taurine increases testicular function in aged rats by inhibiting oxidative stress and apoptosis. Amino Acids. 2015;47:1549-58. PMID: 25957528 DOI: 10.1007/s00726-015-1995-0

Yang W, Huang J, Xiao B, Liu Y, Zhu Y, Wang F, Sun S. Taurine protects mouse spermatocytes from ionizing radiation-induced damage through activation of $\mathrm{Nrf} 2 / \mathrm{HO}-1$ signaling. Cell Physiol Biochem. 2017;44:1629-39. PMID: 29216642 DOI: $10.1159 / 000485762$

Yang Y, Zhang Y, Liu X, Zuo J, Wang K, Liu W, Junbo Ge J. Exogenous taurine attenuates mitochondrial oxidative stress and endoplasmic reticulum stress in rat cardiomyocytes. Acta Biochim Biophys Sin (Shanghai). 2013;45:35967. PMID: 23619568 DOI: 10.1093/abbs/gmt034

Ye X, Kuklenyik Z, Needham LL, Calafat AM. Measuring environmental phenols and chlorinated organic chemicals in breast milk using automated on-line column-switching-high performance liquid chromatography-isotope dilution tandem mass spectrometry. J Chromatogr B Analyt Technol Biomed Life Sci. 2006;831:110-5. PMID: 16377264 DOI: 10.1016/j.jchromb.2005.11.050

Zhang G, Wang, Z, Ling $X$, Zou $P$, Yang $H$, Chen Q, Zhou N, Sun L, Gao J, Zhou Z, Cao J, Ao L. Mitochondrial Biomarkers Reflect Semen Quality: Results from the MARCHS Study in Chongqing, China. PLoS One. 2016;11:e0168823. PMID: 28006017 DOI: 10.1371/journal.pone.0168823 